\title{
Knowledge and Attitude of Teachers in Selected Malaysian Primary School towards Dental Injuries
}

\author{
Syazwani Hassan, Nur Nabila Zulkifly, Annapurny Venkiteswaran, Rohaida \\ Abdul Halim
}

Faculty of Dentistry, Universiti Teknologi MARA, Sungai Buloh, Selangor

${ }^{1}$ Email: annapurny@salam.uitm.edu.my

Received: 14 September 2018

Accepted: 30 October 2018

\section{ABSTRACT}

To ascertain the level of knowledge among primary school teachers towards the management of traumatic dental injuries (TDIs) in school and to determine the preference among teachers regarding the education tools that can be used to increase awareness and knowledge among them. A total of 150 teachers from primary schools in three different districts were included in the study and they were given self-administered questionnaires to be filled. The validated questionnaire was distributed randomly in the selected schools. The questionnaire included two scenarios comprising of tooth fracture and avulsion. Questions regarding awareness and management of these scenarios were asked. All 150 participants answered the questionnaire; of these $74 \%$ were females $26 \%$ were males. $64 \%$ of the participants had received tertiary education. Although $70 \%$ of teachers had obtained first aid training, only $9.3 \%$ of them had received training regrading dental injuries. About 53\% of participants knew the correct answer for the appropriate response to fractured tooth and only 35.3\% managed to correctly answer the question related to appropriate response to an avulsed tooth. Only $38.7 \%$ knew about appropriate rinsing solution and a mere $4.7 \%$ were familiar with proper storage media. Even though the teachers have poor knowledge regarding management of dental injuries, it is reassuring to know that $93 \%$ of them are keen on further training and awareness. More educational programmes need to be introduced to empower the teachers with the relevant knowledge required to deal with dental emergencies.

Keywords: children, dental trauma, emergency, knowledge, teacher meat 


\section{INTRODUCTION}

Traumatic dental injuries are a serious dental public health concern as the rising number of cases can challenge the core problems of caries and periodontal problems [1,2]. Dental trauma is considered a major public health problem as the injuries can affect one's quality of life [3]. It has been well documented that majority of dental injuries among children occur at home and at school [4]. It is reported that dental injuries affect approximately one out of five children in school [5-8] and the age group most susceptible is between $8-12$ years old [9-12].

Among common causes of dental trauma in school going children include falls, blows to the face and sports activities $[13,14]$. The resulting trauma ranges from concussions to maxillofacial injuries. Traumatic dental injuries include concussion, luxation, intrusion, extrusion and avulsion of a tooth. Crown fracture makes up between $26-76 \%$ of the injuries [16], while $30-44 \%$ are luxative injuries [17]. Tooth avulsion can contribute up to $16 \%$ of traumatic dental injuries that occur at school [18]. Unfortunately, tooth avulsion is a complicated affair with frequent and long duration of treatment. This injury has a peak incidence between the ages of 7-11 years old with the maxillary central incisors being the most affected [19]. Avulsion is more common in this age group rather than adults and this is due to the nature of loose periodontal ligament around the teeth and the presence of more cancellous bone [20].

The immediate steps taken to manage an avulsed tooth determines its prognosis and if done properly, the success rate can be as high as 85 to $97 \%$ [9]. For a favourable outcome, the duration between the time of avulsion and replantation must be within the first 15-20 minutes [22]. The manner of handling the tooth determines the success of a tooth replantation procedure. The storage mediums which can be used to transport an avulsed tooth are Hank's balanced salt solution, saliva, milk, vestibule of the mouth, normal saline, or water [23]. The ideal storage medium depends on the composition and osmolarity to maintain the cells viability. Hanks balanced salt solution has superior ability to keep the cells viable, but it is not easily available in Malaysia [23]. 
As accidents frequently happen within the school compound, the immediate steps taken and the appropriate management by teachers will determine how long the tooth will survive and if it can be replanted [12]. School teachers frequently deal with traumatic dental injury at schools, but studies indicate that they lack knowledge in the management of dental trauma [18].

In a study done by Bayrak et al. (2012) [24] in Turkey to evaluate the school teachers' knowledge and attitude to emergency management of dental injuries, $45.5 \%$ of the teachers gave wrong answers regarding emergency management of avulsion case and almost one third of the teachers did not know what to do in such incident. In a similar study done by Mohammad Al-Obaida (2010) [19] in a group of Saudi primary school teachers, 35.3\% of the teachers managed to identify the tooth as a permanent incisor, but $55.2 \%$ gave wrong response regarding emergency management. Alarmingly, $98.2 \%$ of the subjects chose the wrong medium to transport the tooth. Mori et al. (2007) evaluated the knowledge of tooth avulsion of school teachers in Brazil and the findings showed that $75 \%$ of the teachers demonstrated that they would not replant the tooth [25]. In a Senegal study, $49.1 \%$ of the teachers chose to systematically rinse the avulsed tooth. However, their choice of solution reflected their poor knowledge as they picked salt water (20.4\%), antiseptics (13.9\%) and dentrifices (13.6\%) over tap water[26].

Dental injuries mark a long journey for the patients and attending dentist alike. Review appointment are necessary and warranted as some complications can only be seen many months or years post trauma. In severe cases, traumatic dental injuries can cause pulp damage and injuries to the periodontal ligament which can both lead to tooth loss. Management of traumatised teeth should be done immediately and appropriately for long term success. Many studies around the world have shown the lack of knowledge of school teachers with regard to emergency management of traumatic dental injuries [27]. However, there is no study evaluating the knowledge and attitude of school teachers on dental trauma management have been done in Malaysia. 


\section{MATERIALS AND METHODS}

This study was approved by the Universiti Teknologi MARA's ethics committee (600- RMI 5/1/6). The study is a cross sectional questionnaire study conducted among 150 primary school teachers in ten schools in three different districts, Shah Alam, Muar and Tumpat. Expert review of the questionnaire was done to ensure content validity and necessary modifications were made accordingly, wherever applicable.

The questionnaires were modelled based on previous surveys done in Turkey (Byrak et al., 2012), Jordan (Al-Jundi et al., 2005), Israel (Axia Fux-Noy et al., 2010) and Iran (Mesgarzadeh et al., 2009) [18, 24, 2728]. The questions were condensed into 20 items covering the aspects of knowledge and attitude.

The questionnaire was divided into three major parts. The first part included demographic details and experience of the teachers. The second part of the questionnaire consisted of questions assessing subjects' knowledge regarding dental trauma and immediate management options. The respondents were given two case scenarios which were fractured permanent tooth and tooth avulsion and related questions were asked. The third part contained questions on the teachers' satisfaction on the current level of knowledge regarding emergency management of dental injuries, ability to handle dental emergency in school. The respondents were also asked what method would be the best to increase their knowledge of dental trauma.

The questionnaire was personally distributed among the teachers by the researchers. The consent and approval was obtained from the Director of District of Education and headmasters of schools involved. The study was explained to the volunteered respondents beforehand and they were asked to assemble at a common venue in the school at their convenience. Written consent was obtained and all the respondents were assured of strict confidentiality. The questionnaire was distributed to the respondents after giving instructions. Adequate time was given to the respondents to complete the forms. The forms were collected on the same day and it was ensured that the teachers did not use any external references such as books or the internet to obtain the answers. 
The completed forms were compiled and the data was entered into MS excel sheet (Microsoft Corp.) and results was calculated and analysed using SPSS for Windows version 20.1. The chi square test was used to compare the result according to district, level of education and years of experience. Level of significance was set at $p \leq 0.05$.

\section{RESULTS}

\section{Part I: Demographic Features}

Around 200 teachers were approached and invited to participate in this study. Of these, only a total of 150 teachers were willing to answer the questionnaire. There were 50 respondents from each district which are Shah Alam, Muar, and Tumpat. All 150 filled questionnaires were included in the study as they were complete and fulfilled the criteria.

Table 1: Distribution of respondents according to gender and age group

\begin{tabular}{|l|c|}
\hline Gender & $\%$ \\
\hline Male & 24 \\
Female & 76 \\
\hline Age Group (years) & \\
$21-30$ & 15.3 \\
$31-40$ & 41.3 \\
$41-50$ & 31.3 \\
$51-60$ & 12.0 \\
\hline
\end{tabular}

Majority of the respondents (74\%) were females and two thirds of the subjects were between the ages of 31 to 50 years. Language teachers constitute the biggest group of respondents (41.3\%), followed by Science, Mathematics and Technology (32.7\%).

$84(56 \%)$ of the respondents had less than 15 years of teaching experience while $14 \%$ had more than 25 years of experience. The demographic profile indicates that $70 \%$ of the teachers had first aid training during their teachers training but only $14(9.3 \%)$ were trained to deal with dental emergencies as part of their core training. 
With regards to experience dealing with dental injury, only $18(12 \%)$ teachers have dealt with at least one case of dental trauma while in service.

\section{Part II: Knowledge survey}

\section{Scenario A:}

The respondents were given a scenario of an eight years old boy who presented with a broken upper incisor and they were asked to identify whether the tooth was a deciduous or permanent tooth. A total of $74.5 \%$ of the respondents wrongly identified the tooth as a primary tooth while $12.6 \%$ of them answered that they did not know what type of tooth it was. This leaves another $12.9 \%$ of respondents who were able to identify the tooth correctly. Chi-square test shows a significant difference $(p=0.000)$ in the category of tooth identification in Scenario A. However, there was no significant difference noted when a chi- square analysis was done to determine the effect of gender, district, age group, level of education, subject of teaching and previous training in managing emergencies.

In relation to the most appropriate course of action to be taken by the teacher when facing a situation of fractured teeth, $53 \%$ of the respondents chose to contact the parents immediately and advise them to take the child to a dentist. Less than $10 \%$ chose to merely reassure the child and not inform the parents (Figure 1).

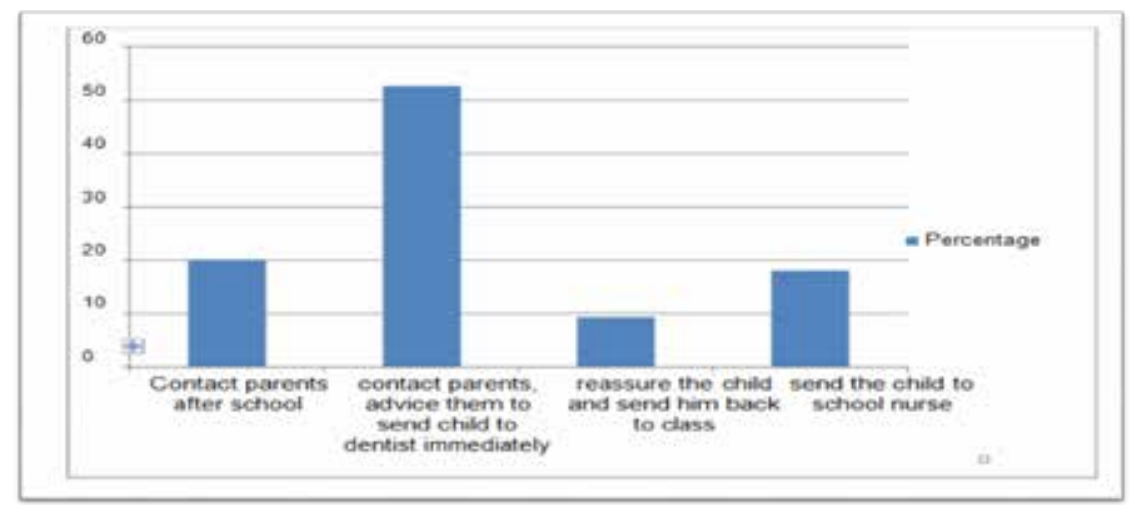

Figure 1: Immediate course of action taken by teachers in the event of fractured upper teeth in an eight years old 


\section{Scenario B:}

The second scenario presented a case of an avulsed upper incisor in a 12 year old girl. For emergency management, only six teachers (4\%) responded ideally by attempting to replant the tooth. Majority of them $(42.7 \%)$ chose to send the child to the nearest hospital.

Regarding the choice of rinsing solution, 66 respondents gave the wrong answer which is mouth-rinse solution, followed by $38 \%$ who chose tap water. For the best transport medium of the tooth, $31.3 \%$ chose salt water. A very small percentage answered correctly, seven out of 150 teachers (4.7\%) chose milk, and four teachers $(2.7 \%)$ answered saliva (Figure $3)$.A chi-square test done to assess the effect of age and experience on the knowledge regarding an avulsed permanent tooth showed no significant differences.

\section{RINSING SOLUTION FOR AVULSED TOOTH}
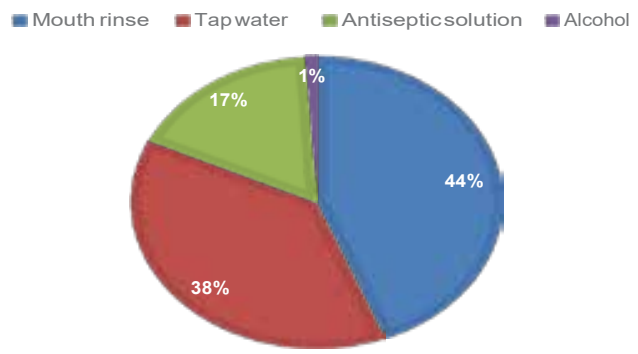

Figure 2: Preferred choice of rinsing solution for avulsed permanent tooth

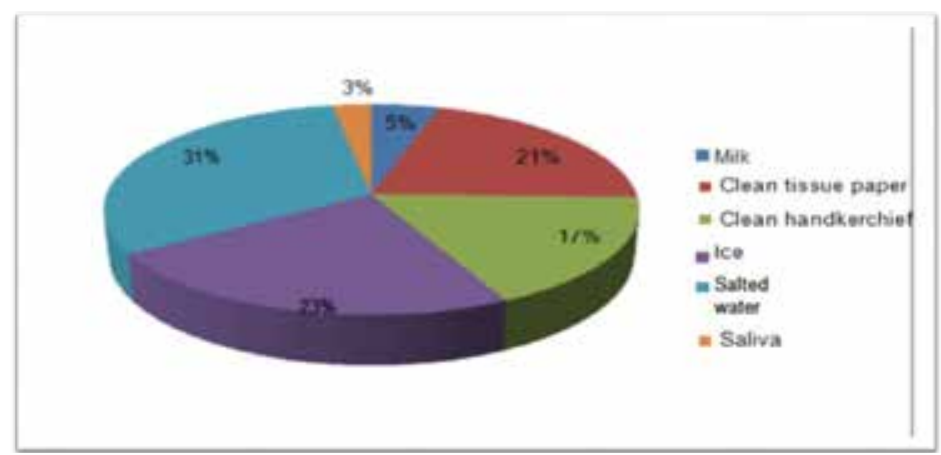

Figure 3: Preferred choice of transport medium for avulsed tooth 


\section{Part III: Attitude survey}

The responses to Part III of the questionnaire reflected self-assessed knowledge and their desire to have further education on dental injury. $84 \%$ of the teachers are not satisfied with their knowledge regarding emergency management of dental injuries. $83 \%$ felt that they are not able to handle a dental emergency in school adequately. With regard of further education, $96.7 \%$ answered positively that they need more knowledge and exposure regarding dental emergencies, with $93.3 \%$ (140 teachers) are interested to have more exposures and skills to deal with such cases. Figure 4 shows that traditional lectures on the topic of dental trauma is among the most preferred tools of gaining knowledge in dental trauma.
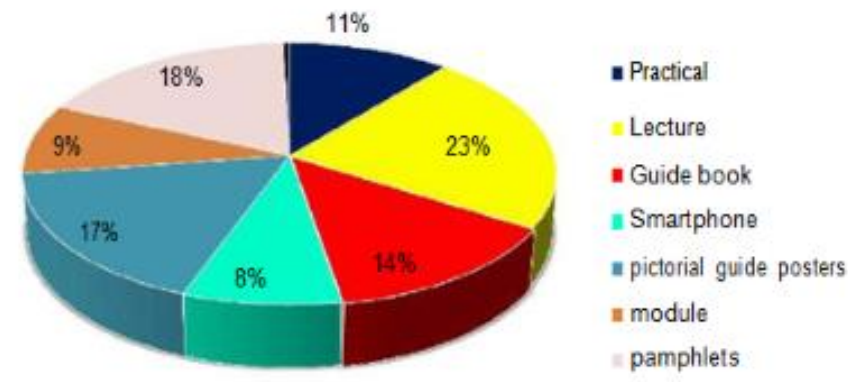

Figure 4: Choice of tools to increase knowledge in dental trauma among teachers

\section{DISCUSSION}

It is imperative that school teachers have at least the basic knowledge to deal with dental trauma as school going children make up a large part of children suffering from injuries. The teacher's knowledge of TDI emergency management is fundamental to the provision of correct care to an injured child [29]. However, most teachers do not receive the necessary orientation related management of various trauma cases [2].

A large proportion $(64 \%)$ of the teachers who participated in this questionnaire were qualified with tertiary education. This is especially important when taking into account the effect of teachers' educational 
background on their knowledge regarding traumatic dental injury. However, our findings of knowledge and confidence does not correspond with findings from Mesgarzadeh et al.(2009) [28] which found that higher level of education and more experienced teachers were more capable of handling a dental injury in the right manner. In this study, there was no significant difference on the level of knowledge based level of education. Although most of the teachers received some form of training in emergency, only $9.3 \%$ of them received any training involving management of dental trauma. Our findings are consistent with previous studies in which primary school teachers reported that they received no training regarding dental trauma $[28,29]$. Surprisingly, among those who reported having received training regarding dental trauma, many failed to give the correct responses to the management of dental trauma, and this finding corroborates with a reported by Chan et al. (2001) [30]. This discrepancy could be due to the fact that the dental module in their training was inadequate. Another possibility is that the training may be forgotten due to the long duration after graduating as a teacher. To address this low level of knowledge, the Ministry of Education in Malaysia should consider making dental trauma education mandatory for primary school teachers.

In this study, $52.7 \%$ of the teachers would rightly contact parents in case of broken tooth and get them to go to a dentist. Reporting to the parents is the golden rule when it comes to dealing with any injury of a child in school. According to McIntyre et al. (2008) [31], teachers are unaware of which dentition is affected when an eight year old loses his tooth. The present study corroborates these findings, as $11.3 \%$ of them marked the broken tooth as a permanent tooth while $88.7 \%$ of them marked either primary tooth or unsure in response to the question addressing a broken central incisor in 8 years old boy.

As the prognosis of an avulsed tooth depends on the time lapse between injury and treatment, it is necessary for either the patient or someone else at the scene to re-implant the tooth immediately [25]. Furthermore, the survival and longevity of an avulsed tooth depends largely on appropriate handling of the tooth to ensure the viability of periodontal ligament cells which cover the root surface. The choice of irrigation for tooth cleansing, extra oral dry time, storage medium for the tooth and urgent attention by the dentist all greatly affect the prognosis of an avulsed tooth [12]. Unfortunately, only 
$4.0 \%$ of teachers recognised that an avulsed tooth should be placed in the socket immediately. This would be the best treatment option with the best long term prognosis [15]. In a study with monkeys, it was shown that the reimplanted teeth after two hours had more root resorption than after 18 minutes [12]. In a Singaporean study, the results showed that $71 \%$ of pre-school teachers there knew the treatment of avulsion [32].

Generally, teachers are not inclined to reposition the tooth in the socket themselves and thus may stem from a few reasons. The teachers feel that they in lack the training and they feel they may inflict more pain for the child. The teachers also may be reluctant as they fear the spread of blood borne diseases and do not want to be responsible for complication which may arise or end up getting sued.

Teachers also gave greater priority to stopping the bleeding which was perceived by most as life threatening [34]. 35\% of the teachers chose to send the child to the dentist with the avulsed tooth in liquid. The choice of a suitable medium and transportation within 30 minutes can yield good long term prognosis [31]. However, the teachers in this study revealed a lack of awareness regarding the best form of rinsing solution and storage media. Only $38.7 \%$ of them stated they would clean the avulsed tooth with tap water and another $61.3 \%$ chose wrong rinsing solution, with $44.0 \%$ of them stated they would clean the avulsed tooth with a mouth-rinse solution. They are unaware that they would be severely decreasing the success of the procedure. The majority of them would seek professional help immediately, but they would choose the wrong storage media, which would reduce the success rate. While $62 \%$ chose to put the avulsed tooth in liquid, only $4.7 \%$ knew the appropriate transport medium is milk, $2.7 \%$ chose saliva and $54.6 \%$ of them wrongly chose salt water and ice as storage media. This findings contradicts with those by Blakytny et al. (2001) [33] and McIntyre et al. (2008) [31] with $45.6 \%$ and $34.0 \%$ respectively chose milk as the most suitable storage media.

Milk serves as an appropriate medium for avulsed tooth for up to three hours because of its optimum osmolarity and $\mathrm{pH}$ composition [35]. The wrong answer options included dry storage such as clean tissue paper and clean handkerchief. In a study by McIntyre et al. (2008) [31], 32.0\% of teachers chose Hanks balanced salt solution (HBSS) as a storage media. 
Hanks balanced salt solution has superior ability to keep the cells viable, but it is not easily accessible [23]. HBSS was not included in this present study as HBSS is not commercially available in Malaysia.

In present study, $84.0 \%$ of teachers agreed that they lack knowledge regarding emergency management of dental injuries and $82.7 \%$ admitted they were not able to handle any dental emergency in school. In line with worldwide research, the teachers in this study clearly lack adequate knowledge regarding the emergency management of avulsed tooth in a child $[18,25,29,20,32,33]$. In the present study however, about $93.3 \%$ of them were interested in having more exposure and skills in dealing with dental emergencies in school.

Mori et al. (2007) carried out an educational campaign about dental trauma in the city of Adamantina, Brazil, and they had a successful outcome after educational campaigns as the school professionals were able to handle dental avulsion cases satisfactorily. This result shows that there is a great need for educational campaigns which can be applied for primary school teachers [25].

\section{CONCLUSION}

The current status of knowledge regarding dental trauma is very poor among primary school teachers. This scenario needs to be improved if we hope to increase the chances of successfully replanting avulsed teeth. The subjects in this study are keen to update their knowledge and as such more educational programmes need to be introduced to empower the teachers with the relevant knowledge. 


\section{REFERENCES}

[1] E. Borssen, AK. Holm, 1997. Traumatic dental injuries in a cohort of 16-year-olds in northern Sweden, Endod Dent Traumatol, Vol. 13(6), pp. 276-280. Doi: https://Doi.org/10.1111/j.1600-9657.1997.tb00055.x

[2] J. E. Todd, 1983. Children's Dental Health in England and Wales. Social Survey Division and Her Majesty's Stationary Office, London.

[3] M.I. Cortes, W. Marcenes, A. Sheiham, 2002. Impact of traumatic injuries to their permanent teeth on the oral health related quality of life in 2-14 year old children, Community Dent Oral Epidemiol, Vol. 30, pp. 193-198.

[4] B. Toure, F. Leye Benoist, B. Faye, A.W. Kane, and S. Kaadioui, 2011. Primary school teacher's knowledge regarding emergency management of avulsed permanent incisors, Journal Of Dentistry, Tehran University, Vol. 8(3), pp. 117-122.

[5] W. Marcenes, N. Al Beiruti, D. Tayfour and S. Issa, 2008. Epidemiology of traumatic injuries to the permanent incisors of 9-12 year old school children in Damascus, Syria, Endod Dent Traumatol, Vol. 15(3), pp. 117-23. Doi: 10.1111/j.1600-9657.1999.tb00767.x.

[6] J.O. Andreasen and J. Ravn, 1972. Epidemiology of traumatic dental injuries to primary and permanent teeth in a Danish population sample, Int J Oral Surg. Vol. 1(5), pp.235-9

[7] L.D. Rajab, 2003. Traumatic dental injuries in children presenting for treatment at the Department of Paediatric Dentistry, University of Jordan, 1997-2000, Dent Traumatol, Vol. 19, pp.6-11. Doi: https:// Doi.org/10.1034/j.1600-9657.2003.00131.x.

[8] J. Traebert, M.A. Peres, V. Blank, R.S. Boell and J.A. Pietruza, 2003. Prevalence of traumatic dental injury and associated factors among 12 year old school children in Florianopolis, Brazil, Dent Traumatology, Vol. 19(1), pp. 15-18. Doi: 10.1034/j.1600-9657.2003.00138.x. 
[9] A.M. Abdellatif and S.A. Hegazy, 2011. Knowledge of emergency management of avulsed teeth among a sample of Egyptian parents, Journal of Advanced Research,. Vol. 2, pp. 157-162. Doi: 10.1016/j. jare.2011.01.002.

[10] U. Mohandas, and G.D. Chandan, 2009. Knowledge, attitude an practice in emergency management of dental injury among physical education teachers: A survey in Bangalore urban schools, $J$ Indian Soc Pedod Prev Dent, Vol. 27(4), pp. 242-248. Doi: 10.4103109704388.57660 .

[11] S.B. Rai and A.K. Munsi, 1998. Traumatic injuries to the anterior teeth among South Kanara school children: A Prevalence study, Journal Indian Society of Pedodontics and Preventive Dentistry, Vol. 10, pp. 44-51

[12] J.O. Andreasen, 1981. Effects of extra-alveolar period and storage media upon periodontal and pulpal healing after replantation of mature permanent incisor in monkeys, Int J Oral Surg. Vol.10(1), pp. 43-53

[13] M.D. Battstone, C. Waters, S.A. Porter and F.N. Monsour, 2004. Treatment delays in paediatric dento- alveolar trauma at a tertiary referral hospital, Aust Dent J. Vol. 49(1), pp. 28-32

[14] R.J. Vergotine and R. Govoni, 2010. Public school educator's knowledge of initial management of dental trauma, Dental Traumatology, Vol. 26(2), pp. 133-136. DOI: 10.1111/j.1600-9657.2009.00854

[15] J.O. Andreasen, F.M. Andreasen and L. Andersson, 2007. Textbook and Color Atlas of Traumatic Injuries to the Teeth, $4^{\text {th }}$ edition. Munksgaard, Copenhagen.

[16] R. Gassner, R. Boschner, T. Tuli and R. Emshoff, 1999. Prevalence of Dental Trauma in 6000 patients with facial injury, Oral Surgery, Oral Medicine, Oral Pathology, Oral Radiology, and Endodontology, Vol. 87, pp. 27-33. Doi: 10.1016/S1079-2104(99)70290-8. 
[17] J.O. Andreasen and F.M. Andreasen, 1993. Luxation Injuries: Textbook and Color Atlas of Traumatic Injuries to the Teeth. $3^{\text {rd }}$ edition. Munksgaard, Copenhagen.

[18] S.H. Al-Jundi, H. Al-Waeili and K. Khairalah, 2005. Knowledge and attitude of Jordanian school health teachers with regards to emergency management of dental trauma, Dental Traumatology, Vol. 21(4), pp. 183-187. Doi: 10.1111/j.1600-9657.2005.00307.x.

[19] M. Al-Obaida, 2010. Knowledge and management of traumatic dental injuries in a group of Saudi primary school teachers, Dental Traumatology, Vol. 26(4), pp. 338-341. Doi:10.1111/j.16009657.2010.00894.x

[20] Harkiran Kaur, Supreet Kaur and Hargundeep Kaur, 2012. Prehospital emergency management of avulsed permanent teeth: Knowledge and attitude of schoolteachers, Indian Journal of Dental Research, Vol. 23(4), pp. 556. Doi: 10.4103/0970-9290.104974.

[21] J.O. Andreasen, M.K. Borum, H.L. Jacobsen and F.M. Andreasen, 1995. Replantation of 400 avulsed permanent incisors. 4. Factors related to periodontal ligament healing, Endod Dent Traumatol, Vol. 11(2), pp. 76-89

[22] K. Emerich and J. Kaczmarek, 2010. First aid for dental trauma caused by sports activities: state of knowledge, treatment and prevention, Sports Med. Vol. 40(5), pp. 361-366. Doi: 10.2165/11530750000000000-00000.

[23] Y. A. Syed, A.M. Khan, M.A. Khan, F. Qazi and N.Z. Ghazali, 2010. Knowledge about the management of avulsed tooth among Karachi school teachers, Pakistan Oral \& Dental Journal, Vol. 30(2), pp. 512520 .

[24] Bayrak S, Sen Tunc E, Sari E, 2012. Evaluation of elementary school teachers' knowledge and attitudes about immediate emergency management of traumatic dental injuries, Oral Health Prev Dent., Vol. 10(3), pp. 253-258. 
[25] G.G Mori, K.H. Leal Turcio, V.P. Baraldi Borro and A.M. Mariusso, 2007. Evaluation of the knowledge of tooth avulsion of school professionals from Adamantina, Sao Paulo, Brazil, Dental Traumatology, Vol. 23(1), pp. 2-5. DOI: 10.1111/j.16009657.2005.00391.x

[26] A.W. Kane, T. Babacar, D. Moustapha, M. Malick, S. Mouhamed and B. Yves, 2011. Attitude and knowledge of primary school teachers of initial management of dental trauma, Journal of Oral Health \& Research, Vol. 2(2), pp. 51-53

[27] A. Fux-Noy, H. Sarnat and E. Emir, 2011. Knowledge of elementary school teachers in Tel- Aviv, Israel, regarding emergency care of dental injuries, Dental Traumatology, Vol. 27(4), pp. 252- 256. DOI: 10.11111/J.1600-9657.2010.00970.x

[28] A.H. Mesgarzadeh, M. Shahamfar and A. Hefzollesan, 2009. Evaluating knowledge and attitudes of elementary school teachers on emergency management of traumatic dental injuries: A study in an Iranian Urban area, Oral Health Prev Dent., Vol. 7(3), pp. 297-308

[29] L.F. Pacheco, P.F. Filho, A. Letra, R. Menezes, G.E. Villoria and S.M Ferreira, 2003. Evaluation of the knowledge of the treatment of avulsions of elementary school teachers of Rio de Janeiro, Brazil, Dent Traumatol, Vol. 19(2), pp. 76-78

[30] A.W.K. Chan, T.K.S. Wong and G.S.P. Cheung, 2001. Lay knowledge of physical education teachers about the emergency management of dental trauma in Hong Kong, Dental Traumatology, Vol. 17(2), pp. 77-85. Doi:10.1034/j.1600-9657.2001.017002077.x

[31] J.D. McIntyre, J.Y. Lee, M. Trope and W.F. Vann, 2008. Elementary school staff knowledge about dental injuries, Dental Traumatology, Vol. 24(3), pp. 289-298. Doi: 10.1111/j.1600-9657.2007.00542.x.

[32] V. Sae-Lim, and L.P. Lim, 2011. Dental trauma management awareness of Singapore pre-school teachers, Dental Traumatology, Vol. 17(2), pp. 71-76. Doi:10.1034/j.1600- 9657.2001.017002071.x. 
[33] C. Blakytny, C. Surbuts, A. Thomas, and M.L. Hunter, 2001. Avulsed permanent incisors: knowledge and attitudes of primary school teachers with regard to emergency management, Int J Paediatric Dent. Vol. 11(5), pp. 327-332.

[34] N.D. Shashikiran, V.V.S. Reddy and N.B. Nagaveni, 2006. Knowledge and attitude of 2000 parents with regard to avulsed permanent incisors and their emergency management, in and around Davangere, J Indian Soc Pedod Prev Dent., Vol. 24(3), pp. 116-21

[35] L. Blomlof, S. Lindskog and L. Hammarstrom, 1981. Periodontal healing of exarticulted monkey teeth stored in milk or saliva, European Journal of Oral Sciences, Vol. 8(1), pp. 251-259. Doi:10.1111/j.1600-0722.1981.tb01679. 